\title{
Progress Report 2011: Understanding compound phase transitions in Heusler alloy giant magnetocaloric materials:
}

Subcontract Grant Number: DE-SC0005295 (Under Grant No. DE-FG02-06ER46291)

(Report Period: July 1, 2010 - September 14, 2011)

\author{
Naushad Ali (PI) \\ Southern Illinois University \\ Department of Physics \\ Carbondale, IL 62901 \\ nali@physics.siu.edu
}

\author{
Shane Stadler (Co-PI, Subcontractor) \\ Louisiana State University \\ Department of Physics \& Astronomy \\ Baton Rouge, LA 70803 \\ stadler@phys.lsu.edu
}

\section{INTRODUCTION}

The original impetus for this research was our observation of the giant magnetocaloric effect (MCE) in the Heusler alloy $\mathrm{Ni}_{2} \mathrm{Mn}_{1-\mathrm{x}} \mathrm{Cu}_{\mathrm{x}} \mathrm{Ga}$. ${ }^{1}$ We found an extremely large magnetic entropy change $\Delta \mathrm{S}_{\mathrm{M}}=-64$ $\mathrm{J} \cdot \mathrm{Kg}^{-1} \cdot \mathrm{K}^{-1}=-532 \mathrm{~J} \cdot \mathrm{cm}^{-3} \cdot \mathrm{K}^{-1}$ at $308 \mathrm{~K}$ for a magnetic field change $\Delta H=5 \mathrm{~T}$. In this case, the large MCE was due to a compound magnetostructural transition that was formed by the coalescence of the martensitic and Curie transition temperatures $\mathrm{T}_{\mathrm{M}}$ and $\mathrm{T}_{\mathrm{C}}$, respectively, for the concentration $\mathrm{x}=0.25$ (Fig. 1). This project is focused on the behaviors of magnetostructural phase transitions and the corresponding induced physical phenomena in Ni-MnGa Heusler alloy systems. In this current report, we describe a wide variety of newly observed physical phenomena including inverse MCE,

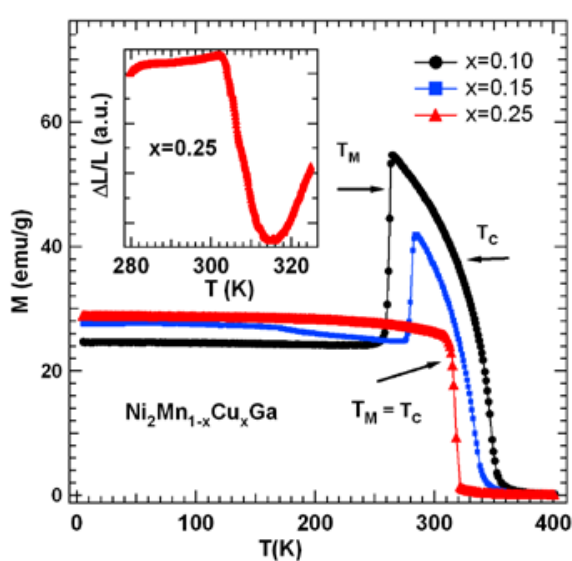

Fig. 1. Magnetization as a function of concentration and temperature with an applied field of $1 \mathrm{kOe}$. (Inset) Thermal expansion for $\mathrm{x}=0.25$. magnetoresistance, and exchange bias.

\section{CURRENT RESULTS (Highlights)}

(i) Effect of partial substitution of $\mathrm{Ni}$ by $\mathrm{Co}$ on the magnetic and magnetocaloric preoperties of $\mathbf{N i}_{50} \mathbf{M n}_{35} \mathbf{I n} \mathbf{n}_{15}$ Heusler alloys (J. Appl. Phys. 109, 07 A916172503 (2011))

The magnetic and magnetocaloric properties of $\mathrm{Ni}_{48} \mathrm{Co}_{2} \mathrm{Mn}_{35} \mathrm{In}_{15}$ were studied using magnetization and heat capacity measurements. The magnetic entropy change $\left(\Delta S_{M}\right)$ was evaluated from both magnetizing and demagnetizing fields. An inverse $\Delta S_{M}$ for the magnetizing and demagnetizing processes were found to be 20.5 and $18.5 \mathrm{~J} \mathrm{~kg}^{-1} \mathrm{~K}^{-1}$, respectively, for $\Delta \mathrm{H}=5$ 
$\mathrm{T}$ at the martensitic transition $\left(\mathrm{T}=\mathrm{T}_{\mathrm{M}}\right)$. The normal $\Delta \mathrm{S}_{\mathrm{M}}$ was found to be $-5.4 \mathrm{~J} \mathrm{~kg}^{-1} \mathrm{~K}^{-1}$ for both fields at the paramagnetic/ferromagnetic transition $\left(T=T_{C}\right)$. The effective refrigeration capacity at $T_{M}$ and $T_{C}$ for magnetizing field was found to be 268 and $243 \mathrm{~J} / \mathrm{kg}$ (285 and $243 \mathrm{~J} / \mathrm{kg}$ for the demagnetizing field), respectively. We have also estimated the density of states, the Debye temperature, and the inverse adiabatic temperature change to be 4.93 states/eV f.u., $314 \mathrm{~K}$, and $3.7 \mathrm{~K}$, respectively, from the measured heat capacity data (Fig. 2).
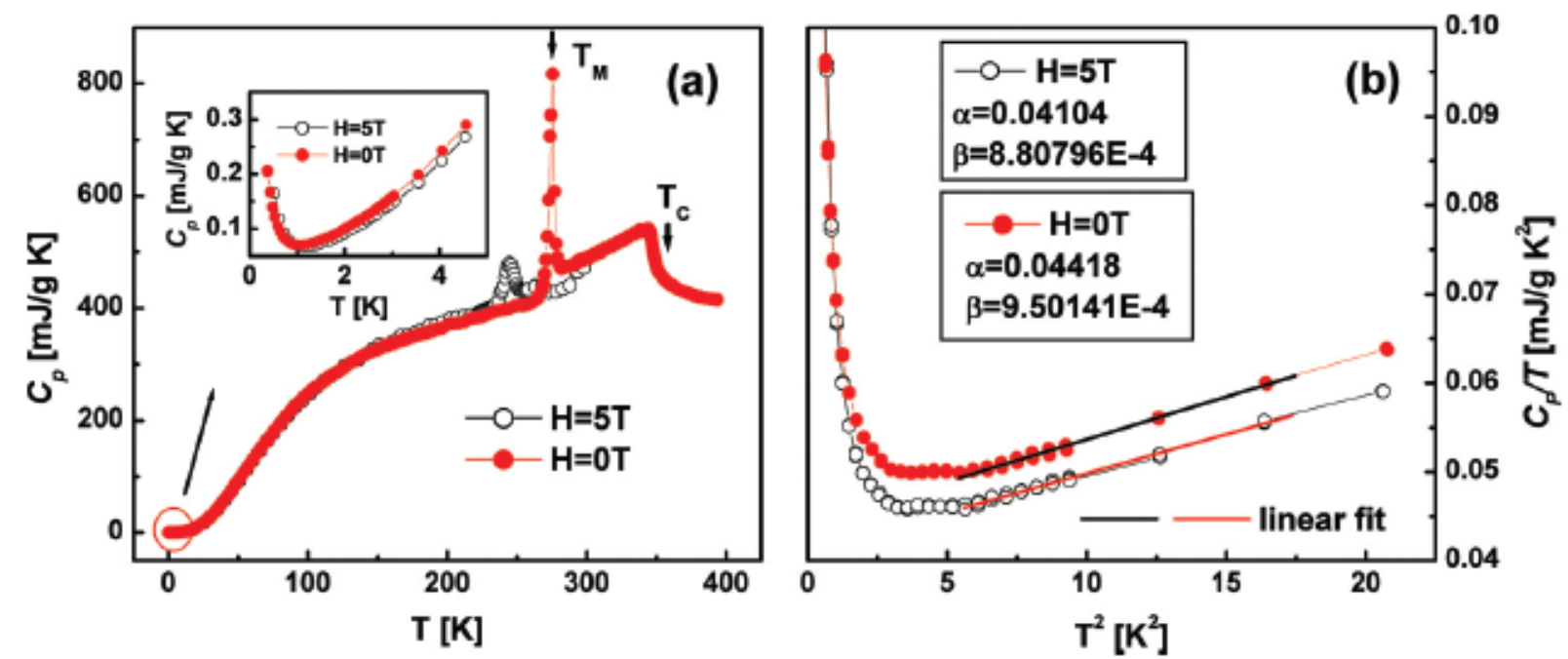

Fig. 2. Heat capacity (Cp) of $\mathrm{Ni}_{48} \mathrm{Co}_{2} \mathrm{Mn}_{35} \mathrm{In}_{15}$ as a function of temperature at $\mathrm{H}=0$ and $5 \mathrm{~T}$ [(inset) the magnified version of low temperature $C p]$. (b) Low temperature $C p / T$ vs $T_{2}$ linear fit data for $\mathrm{H}=0$ and $5 \mathrm{~T}$.

\section{(ii) Direct measurement of the adiabatic temperature change in Heusler Alloys}

(Appl. Phys. Lett. 98, 131911 (2011))

The adiabatic temperature changes $\left(\Delta \mathrm{T}_{\mathrm{ad}}\right)$ in the vicinity of the Curie and martensitic transition temperatures of $\mathrm{Ni}_{50} \mathrm{Mn}_{35} \mathrm{In}_{15}$ and $\mathrm{Ni}_{50} \mathrm{Mn}_{35} \mathrm{In}_{14} \mathrm{Z}$ ( $\mathrm{Z}=\mathrm{Al}$ and $\mathrm{Ge}$ ) Heusler alloys have been studied using an adiabatic magnetocalorimeter in temperature interval of $250-350 \mathrm{~K}$ for applied magnetic field changes up to $\Delta H=1.8 \mathrm{~T}$. The largest measured changes were $\Delta \mathrm{T}_{\text {ad }}=-2 \mathrm{~K}$ and $2 \mathrm{~K}$ near the martensitic (first order) and ferromagnetic (second order) transitions for $\Delta H=1.8 \mathrm{~T}$, respectively. It was observed that $\left|\Delta \mathrm{T}_{\text {ad }}\right| \approx 1 \mathrm{~K}$ for relatively small changes in $\Delta \mathrm{H}=1$ $\mathrm{T}$ for both types of transitions. Therefore these materials should be further explored as potential working materials in magnetic refrigeration applications. 

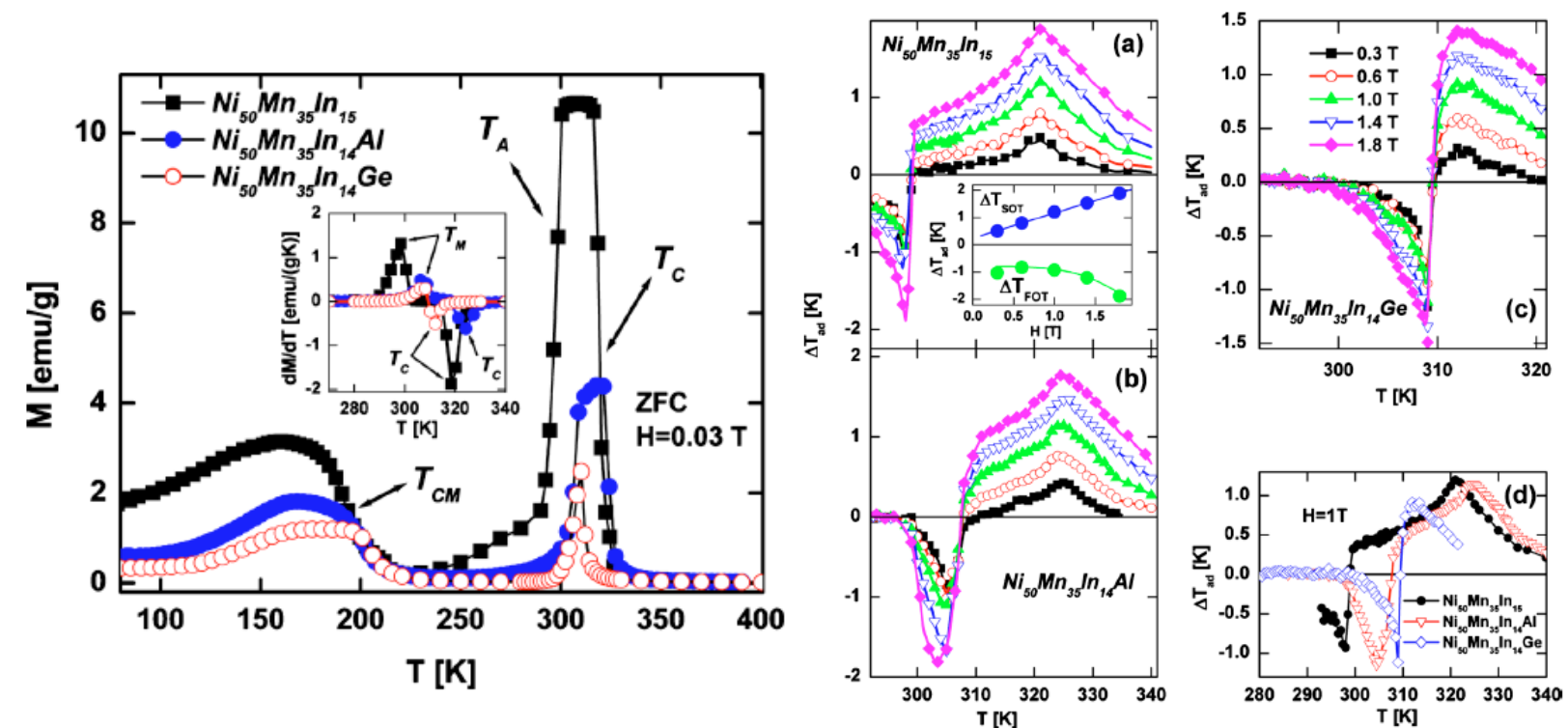

Fig 3. (Left) ZFC magnetization curves $M(T)$ for $\mathrm{Ni}_{50} \mathrm{Mn}_{35} \mathrm{In}_{15}, \mathrm{Ni}_{50} \mathrm{Mn}_{35} \mathrm{In}_{14} \mathrm{Al}$, and $\mathrm{Ni}_{50} \mathrm{Mn}_{35} \mathrm{In}_{14} \mathrm{Ge}$ Heusler alloys, obtained at $\mathrm{H}=0.03 \mathrm{~T}$. (Right) (a-c) The adiabatic temperature changes obtained at different magnetic fields (as it legend in Fig.3c) and temperatures for $\mathrm{Ni}_{50} \mathrm{Mn}_{35} \mathrm{In}_{15}, \mathrm{Ni}_{50} \mathrm{Mn}_{35} \mathrm{In}_{14} \mathrm{Al}$, and $\mathrm{Ni}_{50} \mathrm{Mn}_{35} \mathrm{In}_{14} \mathrm{Ge}$. (d): Adiabatic temperature change $\Delta \mathrm{T}_{\text {ad }}$ as a function of temperature (T) for $\Delta \mathrm{H}=10 \mathrm{kOe}$ for $\mathrm{Ni}_{50} \mathrm{Mn}_{35} \mathrm{In}_{15}, \mathrm{Ni}_{50} \mathrm{Mn}_{35} \mathrm{In}_{14} \mathrm{Al}$, and $\mathrm{Ni}_{50} \mathrm{Mn}_{35} \mathrm{In}_{14} \mathrm{Ge}$. Inset of Fig 1(a): The maxima of $\mathrm{T}$ ad as a function of applied magnetic field (H). The results have been detected for magnetic fields ramped at a rate of $2 \mathrm{~T} / \mathrm{sec}$.

Negative and positive changes in sample temperature were found, as expected, in the presence of external magnetic fields in vicinity of the FOT and SOT, respectively (see Fig. 3 (Right)). The magnitudes of $\Delta \mathrm{T}_{\mathrm{ad}}$ were found to be similar (but opposite in sign) at both transitions. Such behavior may be related to the similar nature of the transitions: a ferromagnetic to paramagnetic transition at $\mathrm{T}_{\mathrm{C}}$, and an inverse of that transition at $\mathrm{T}_{\mathrm{M}}$. The maxima of $\Delta \mathrm{T}_{\mathrm{ad}}$ are linear function of applied field for the SOT but slightly change at low magnetic fields (0.3-1.0 T) for the FOT (see inset of Fig. 3 (a)) and increase nonlinearly at $\mathrm{H}>1.0 \mathrm{~T}$. The maxima of $\Delta \mathrm{T}_{\mathrm{ad}}$ are slightly smaller (by about 20\%) for $\mathrm{Ni}_{50} \mathrm{Mn}_{35} \mathrm{In}_{14} \mathrm{Ge}$ compared to the other alloys for both transitions. The FOT and SOT transition temperature ranges for this compound nearly overlap (see Fig. 3 (Left)), and the ferromagnetic ordering in austenitic phases is incomplete. Thus the magnetization of $\mathrm{Ni}_{50} \mathrm{Mn}_{35} \mathrm{In}_{14} \mathrm{Ge}$ above $\mathrm{T}_{\mathrm{M}}$ is smaller than that observed for $\mathrm{Ni}_{50} \mathrm{Mn}_{35} \mathrm{In}_{14} \mathrm{Al}$ and $\mathrm{Ni}_{50} \mathrm{Mn}_{35} \mathrm{In}_{15}$, and this difference in magnetic order results in a decrease in $\Delta T_{\text {ad. }}$.

The MCE at low magnetic fields is of particular importance from an application point of view. As one can see from Fig. 3 (d), the change in the sample temperatures remains rather large (about $1 \mathrm{~K}$ ) for both transitions for a relatively small magnetic field change of $1.0 \mathrm{~T}$. The maxima of $\Delta \mathrm{T}_{\mathrm{ad}}$ at the SOT are shifted to lower and higher temperature regions for $\mathrm{Ni}_{50} \mathrm{Mn}_{35} \mathrm{In}_{14} \mathrm{Ge}$ and $\mathrm{Ni}_{50} \mathrm{Mn}_{35} \mathrm{In}_{14} \mathrm{Al}$, respectively, compared to the parent compound. The temperature of the maximum of $\Delta \mathrm{T}_{\text {ad }}$ at the FOT increases from $298 \mathrm{~K}$ to $309 \mathrm{~K}$ for $\mathrm{Ni}_{50} \mathrm{Mn}_{35} \mathrm{In}_{15}$, following the changes in $\mathrm{T}_{\mathrm{M}}$. 
(iii) Large inverse magnetic entropy changes and magnetoresistance in $\mathrm{Ni}_{50-\mathrm{x}} \mathrm{Co}_{\mathrm{x}} \mathrm{Mn}_{32}$ y $\mathbf{F e}_{\mathbf{y}} \mathbf{G a}_{18}$ (Appl. Phys. Lett. 97, 062505 (2010))

Significantly large inverse magnetic entropy changes $\left(\Delta \mathrm{S}_{\mathrm{M}}\right)$ and magnetoresistance $(\mathrm{MR})$ were observed at the inverse martensitic phase transitions of the Ga-based magnetic shape memory Heusler alloys: $\mathrm{Ni}_{50-\mathrm{x}} \mathrm{Co}_{\mathrm{x}} \mathrm{Mn}_{32-\mathrm{y}} \mathrm{Fe}_{\mathrm{y}} \mathrm{Ga}_{18}$. The crystal structures of alloys were tetragonal at $300 \mathrm{~K}$ and the phase transition temperatures and magnetic properties were found to be correlated with the degree of tetragonal distortion. The maximum peak values of the $\Delta \mathrm{S}_{\mathrm{M}}$ and $\mathrm{MR}$ at $\mathrm{H}=5 \mathrm{~T}$ were determined as $\approx(+) 31 \mathrm{~J} \mathrm{Kg}-1 \mathrm{~K}-1$ and $\approx 21 \%$, respectively, for $x=8$ and $y=2$. The relatively small hysteretic loss and large refrigeration capacity observed in this system make these compounds promising materials for applications. As shown in $\mathrm{M}(\mathrm{T})$ for $\mathrm{x}=0$ and $y=0$, the sample possesses only a single transition at $360 \mathrm{~K}$ within the upper temperature limit of $400 \mathrm{~K}$ (see Fig. 4(a)). This, together with the room temperature $\mathrm{XRD}$, revealed that this transition observed in magnetization curve is due to the Curie temperature of the martensitic phase.

The phase diagram for $\mathrm{Ni}_{42} \mathrm{Co}_{8} \mathrm{Mn}_{32-\mathrm{y}} \mathrm{Fe}_{\mathrm{y}} \mathrm{Ga}_{18}$ is

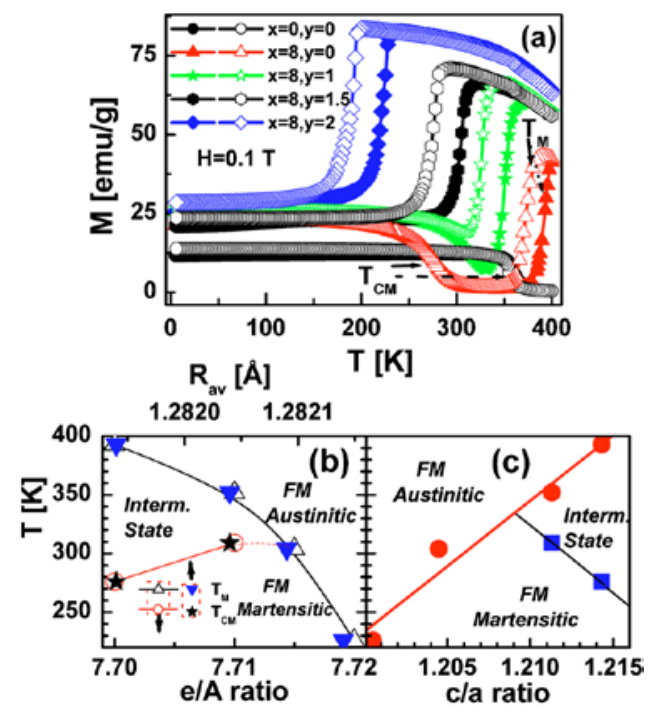

Fig 4. (a) ZFC (closed symbols) and FCC (open symbols) magnetization $[\mathrm{M}(\mathrm{T})]$ for $\mathrm{Ni}_{50-\mathrm{x}} \mathrm{Co}_{\mathrm{x}} \mathrm{Mn}_{32-\mathrm{y}} \mathrm{Fe}_{\mathrm{y}} \mathrm{Ga}_{18}$. Temperature phase diagrams as a function of (b) the average metallic radii and e/A ration, and (c) the c/a ratio at $\mathrm{H}=0.1 \mathrm{~T}$. shown in Figs. 4(b) and 4(c). As can be seen from Fig. 4(b), three magnetic states can be observed in $\mathrm{Ni}_{42} \mathrm{Co}_{8} \mathrm{Mn}_{32-\mathrm{y}} \mathrm{Fe}_{\mathrm{y}} \mathrm{Ga}_{18}$ : (i) a low temperature FM martensitic phase; (ii) an AFM or PM phase in the intermediate state $\left(\mathrm{T}_{\mathrm{CM}}<\mathrm{T}<\mathrm{T}_{\mathrm{M}}\right)$; and (iii) a high temperature FM austenitic phase. It was found that an increase in the Fe concentration increases the e/A ratio (or $\mathrm{R}_{\mathrm{av}}$ ) and $\mathrm{T}_{\mathrm{CM}}$, and at a critical value of e/A, $\mathrm{T}_{\mathrm{CM}}$ and $\mathrm{T}_{\mathrm{M}}$ overlaps. $\mathrm{T}_{\mathrm{M}}$ decreases and tends to disappear with increasing e/A ratio. In the XRD phase diagram, an inflection point was observed at $\mathrm{c} / \mathrm{a}=1.21$. It can also be seen from Fig. 4(a) that $\mathrm{Ni}_{42} \mathrm{Co}_{8} \mathrm{Mn}_{32-\mathrm{y}} \mathrm{Fe}_{\mathrm{y}} \mathrm{Ga}_{18}$ undergoes multiple transitions: (i) at $\mathrm{T}_{\mathrm{CM}}$, and (ii) at $\mathrm{T}_{\mathrm{M}}$ when c/a $<1.21$ $\left(\mathrm{T}_{\mathrm{CM}}\right.$ and $\mathrm{T}_{\mathrm{M}}$ overlap when $\left.\mathrm{c} / \mathrm{a}=1.21\right)$. Band structure calculations revealed that tetragonal distortion plays an important role in the martensitic phase stability of Heusler alloys. Thus, the $\mathrm{c} / \mathrm{a}$ ratio can be an essential factor that influences the structural transition. The maximum change in e/A (0.26\%) [or $\mathrm{R}_{\mathrm{av}}(0.016 \%)$ ] is much lower than the maximum change in c/a (1.38\%) in $\mathrm{Ni}_{42} \mathrm{Co}_{8} \mathrm{Mn}_{32-\mathrm{y}} \mathrm{Fe}_{\mathrm{y}} \mathrm{Ga}_{18}$. As can be seen from Fig. 4(c), $\mathrm{T}_{\mathrm{M}}$ and $\mathrm{T}_{\mathrm{CM}}$ are linear functions of the $\mathrm{c} / \mathrm{a}$ ratio. Therefore, it is most likely that the c/a ratio is the main factor affecting the observed phase transition temperatures. 


\section{WORKS IN PROGRESS}

\section{(i) The adiabatic temperature changes (direct and indirect measurements) in vicinity of the first order paramagnetic-ferromagnetic transition of the Ni-In-Mn-B system}

In this work the studies of magnetic, magnetotransport and magnetocaloric effects near room temperature and in magnetic fields up to18 kOe (including specific heat and direct measurements of adiabatic temperature changes) are presented for the $\mathrm{Ni}_{50} \mathrm{Mn}_{34.8} \mathrm{In}_{15.2-}$ ${ }_{\mathrm{x}} \mathrm{B}_{\mathrm{x}}$ system where coupled (PM austenite - FM martensite) transitions were observed.

It has been shown that the doping of small amount of boron does not affect $\mathrm{T}_{\mathrm{C}}$, but results in a significant increase of $\mathrm{T}_{\mathrm{M}}$ and $\mathrm{T}_{\mathrm{CM}}$. As consequence the first order paramagneticferromagnetic transition at $T_{C}$ was observed even for $x=1$. The adiabatic temperature changes of about $1.6 \mathrm{~K}$ has been found for the applied magnetic field changes $\Delta \mathrm{H}=18 \mathrm{kOe}$ in the vicinity of $\mathrm{T}=323 \mathrm{~K}$ (see Fig.1). The magnetic entropy and adiabatic temperature changes have been estimated from thermomagnetic and specific heat measurements. The differences in the results of direct and indirect measurements of MCE parameters will be

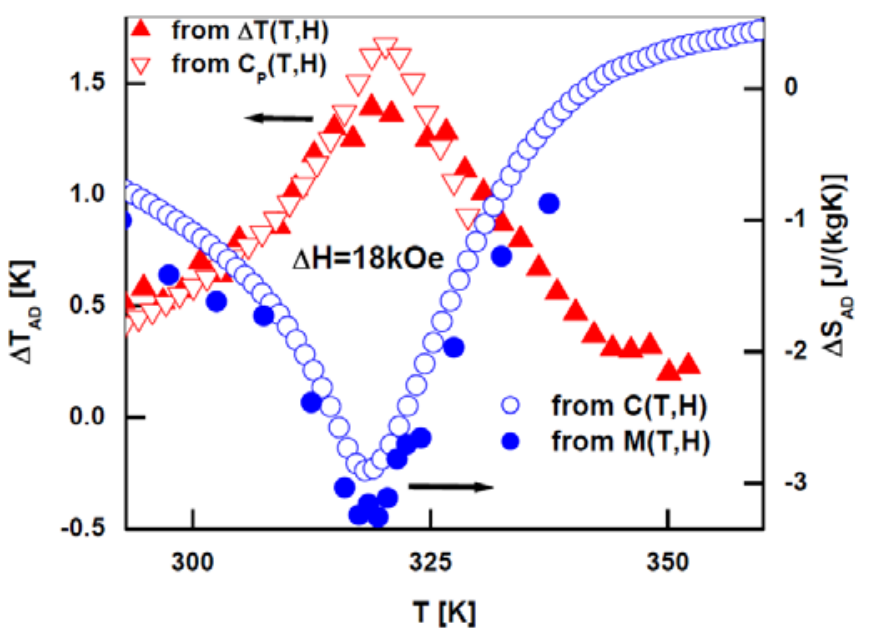

Fig 6. (a) ZFC (closed symbols) and FCC (open symbols) magnetization $[\mathrm{M}(\mathrm{T})]$ for $\mathrm{Ni}_{50-\mathrm{x}} \mathrm{Co}_{\mathrm{x}} \mathrm{Mn}_{32-\mathrm{y}} \mathrm{Fe}_{\mathrm{y}} \mathrm{Ga}_{18}$. Temperature phase diagrams as a function of (b) the average metallic radii and e/A ration, and (c) the c/a ratio at $\mathrm{H}=0.1 \mathrm{~T}$.

\section{OTHER ACTIVITIES}

Presentations at Professional Conferences:

1. Phase transitions, magnetotransport, and magnetocaloric effects in quaternary Ni-Mn-In-Y Heusler alloys”, I. Dubenko, V. Prudnikov, A. Granovsky, A. Pathak, S. Stadler, and N. Ali ( invited talk) Moscow International Seminar on Magnetism (MISM)-2011.

2. The Effect of Partial Substitution of $\mathrm{Ni}$ by $\mathrm{Co}$ on the Magnetic and Magnetocaloric Properties of $\mathrm{Ni}_{50} \mathrm{Mn}_{35} \mathrm{In}_{15}$ Heusler alloy, A. K. Pathak, I. Dubenko, Y. Xiong, P. W. Adams, S. Stadler, and N. Ali 55 ${ }^{\text {th }}$ Annual Conference on Magnetism and Magnetic Materials, Atlanta, GA, Nov 14-18, (2010).

3. Magnetic and Magnetocaloric Properties of $\mathrm{Gd}_{6} \mathrm{X}_{2} \mathrm{Si}_{3}(\mathrm{X}=\mathrm{Ni}, \mathrm{Co})$ and $\mathrm{Ln}_{6} \mathrm{Co}_{2} \mathrm{Si}_{3}(\mathrm{Ln}=\mathrm{Pr}$, La) A. K. Pathak, I. Dubenko, S. Stadler, and N. Ali, 55 ${ }^{\text {th }}$ Annual Conference on Magnetism and Magnetic Materials, Atlanta, GA, Nov 14-18, (2010). 
4. Magnetic, Electrical and Inverse Magnetocaloric Effects in Co and Fe doped Ni-Mn-Ga Heusler alloys, A. K. Pathak, I. Dubenko, S. Stadler, and N. Ali, Materials Research Society (MRS) Fall meeting, Boston, MA, Nov. 29-Dec 3, (2010).

5. The effect of partial substitution of $\mathrm{Ni}$ by $\mathrm{Co}$ on the magnetic and electrical properties of $N i_{50} M_{35} I_{15}$ Heusler alloy, A. K. Pathak, I. Dubenko, S. Stadler, and N. Ali11 ${ }^{\text {th }}$ Joint MMMINTERMAG Conference, Washington, DC, Jan 18-22, (2010).

6. Magnetism and magnetocaloric effects in $\mathrm{Ni}_{50} \mathrm{Mn}_{35-\mathrm{x}} \mathrm{Co}_{x} \mathrm{I} n_{15}$ Heusler alloys, A. K. Pathak, I. Dubenko, S. Stadler, and N. Ali $11^{\text {th }}$ Joint MMM-INTERMAG Conference, Washington, DC, Jan 18-22, (2010).

\section{IDENTIFICATION OF PERSONNEL}

One of DOE's objectives is to build the workforce and talents in energy related research. This project under which this research is subcontracted has already graduated a Ph.D. student (M. Khan) who is continuing research in this field in his new position at Ames National Lab at Iowa State University. Arjun Pathak has defended his Ph.D. dissertation and is now employed as a postdoctoral researcher at the National High Magnetic Fields Laboratory at Florida State University.

\section{List of Personnel:}

\section{** Shane Stadler (Co-PI, Subcontracting at LSU)}

Naushad Ali (PI)

Igor Dubenko (Postdoctoral Researcher)

Tapas Samanta (Posdoctoral Researcher)

Arjun Pathak (Graduate Student—funded through this project)

\section{CURRENT AND PENDING FEDERAL SUPPORT}

NSF-CAREER Seeking Half-Metallic Alloys

Amount: \$483K

PI: Stadler June 1, 2006—May 31, 2012 (CURRENT)

\section{List of publications (since last report)}

1. Magnetocaloric properties of $\mathrm{Ni}_{2} \mathrm{Mn}_{1-x} \mathrm{Cu}_{x} \mathrm{Ga}$,Shane Stadler, Mahmud Khan, Joseph Mitchell, Naushad Ali, Angelo M. Gomes, Igor Dubenko, Armando Y. Takeuchi, and Alberto P. Guimarães, Appl. Phys. Lett, 88, 192511 (2006). (Not from this reporting period).

2. A. P. Kazakov, V. N. Prudnikov, A. B. Granovsky, A. P. Zhukov, J. Gonzalez, I. Dubenko, A. K. Pathak, S. Stadler, N. Ali, Direct measurements of field-induced adiabatic temperature 
changes near compound phase transitions in Ni-Mn-In based Heusler alloys, Appl. Phys. Lett. (accepted, 2011).

3. A. K. Pathak, I. Dubenko, S. Stadler, N. Ali, Magnetic and Magnetocaloric Properties of $\mathrm{Gd}_{6} \mathrm{X}_{2} \mathrm{Si}_{3}(\mathrm{X}=\mathrm{Ni}, \mathrm{Co})$ and $\mathrm{Ln}_{6} \mathrm{Co}_{2} \mathrm{Si}_{3}$ ( $\mathrm{Ln}=\mathrm{Pr}, \mathrm{La}$ ), J. Appl. Phys. (accepted, April, 2011).

4. A. K. Pathak, I. Dubenko, Y. Xiong, P. W. Adams, S. Stadler, and N. Ali, The Effect of Partial Substitution of $\mathrm{Ni}$ by Co on the Magnetic and Magnetocaloric Properties of $\mathrm{Ni}_{50} \mathrm{Mn}_{35} \mathrm{In}_{15}$ Heusler alloy J. Appl. Phys. (accepted, April, 2011).

5. A. K. Pathak, I. Dubenko, S. Stadler, N. Ali, Temperature and field induced strain in polycrystalline $\mathrm{Ni}_{50} \mathrm{Mn}_{35} \mathrm{In}_{15-\mathrm{x}} \mathrm{Si}_{x}$ magnetic shape memory Heusler alloys, J. Alloys. and Comps. 509 (2011) 1106-1110.

6. V. N. Prudnikov, A. P. Kazakov, I. S. Titov, Ya.N. Chovarskii, N. S. Perov, A. B. Granovskii, I.S. Dubenko, A. K. Pathak, N. Ali, A. P. Zhukov, J. Gonzales, Quasimagnetism and exchange anisotropy in Ni-Mn-Co-In Heusler alloys, Physics of the Solid State, 53, (2011) 3490-493.

7. V. N. Prudnikov, A. P. Kazakov, I. S. Titov, N. S. Perov, A. B. Granovskii, I. S. Dubenko, A. K. Pathak, N. Ali, A. P. Zhukov, J. Gonzales, Hall Effect in a Martensitic Transformation in Ni-Co-Mn-In Heusler Alloys , JETP Letters, 92, (2010) 666-670.

8. A. K. Pathak, I. Dubenko, H. E. Karaca, S. Stadler, N, Ali, Large inverse magnetic entropy changes and magnetoresistance in the vicinity of a field-induced martensitic transformation in $\mathrm{Ni}_{50-x} \mathrm{Co}_{x} \mathrm{Mn}_{32-y} \mathrm{Fe}_{y} \mathrm{Ga}_{18}$, Appl. Phys. Lett. 97062505 (2010). DOI:10.1063/1.3467460.

9. I. Dubenko, A. K. Pathak, N. Ali, Ya. Kovarskii, V. N. Prudnikov, N. S. Perov, A. B. Granovsky, Magnetotransport properties of Ni-Mn-In Heusler Alloys: Giant Hall angle, J. Phys.: Conf. Ser, 200052005 (2010).

10. A. K. Pathak, I. Dubenko, C. Pueblo, S. Stadler, and N. Ali, The effect of partial substitution of $\mathrm{Ni}$ by $\mathrm{Co}$ on the magnetic and electrical properties of $\mathrm{Ni}_{50} \mathrm{Mn}_{35} \mathrm{In}_{15}$ Heusler alloy, IEEE Trans. Magn. 46 (2010) 1444-1446. DOI: 10.1109/TMAG.2010.2043924

11. A. K. Pathak, I. Dubenko, C. Pueblo, S. Stadler, and N. Ali, Magnetoresistance and magnetocaloric effect at a structural phase transition from a paramagnetic martensitic state to a paramagnetic austenitic state in $\mathrm{Ni}_{50} \mathrm{Mn}_{36.5} \mathrm{In}_{13.5}$ Heusler alloys, Appl. Phys. Lett. 96 172503 (2010). DOI: $10.1063 / 1.3422483$

12. A. K. Pathak, I. Dubenko, C. Pueblo, S. Stadler, and N. Ali, Magnetism and magnetocaloric effect in $\mathrm{Ni}_{50} \mathrm{Mn}_{35-x} \mathrm{Co}_{x} \mathrm{In}_{15}$ Heusler alloys, J. Appl. Phys. 107 09A907 (2010).

13. A. K. Pathak, P. Basnyat, I. Dubenko, S. Stadler, and N. Ali, Magnetic, magnetocaloric and magnetoelastic properties of $\mathrm{La}\left(\mathrm{Fe}_{1-x} Z_{x}\right)_{11.4} \mathrm{Si}_{1.6}(\mathrm{Z}=\mathrm{Ni}, \mathrm{Cu}, \mathrm{Cr}, \mathrm{V})$ compounds, J. Magn. Magn. Mater. 322 (2010) 692. 